\title{
Lung Transplantation and Lung Cancer: Is There a Link?
}

\author{
Geert M. Verleden ${ }^{\mathrm{a}}$ Andrew J. Fisher ${ }^{\mathrm{b}, \mathrm{c}}$

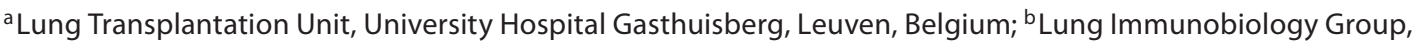 \\ Institute of Cellular Medicine, Newcastle University, and 'Institute of Transplantation, Freeman Hospital, \\ Newcastle Upon Tyne, UK
}

\section{Key Words}

Lung transplantation $\cdot$ Bronchial carcinoma $\cdot$ Chimerism

\begin{abstract}
Lung transplantation offers a major survival benefit in selected patients with end-stage pulmonary disease. In recent years, there is accumulating evidence of an increase in solid organ tumors and especially in primary lung cancer. There is also some anecdotal evidence that lung transplantation may be beneficial as a treatment option in some patients with lung cancer, such as the ones with extensive bronchoalveolar cell carcinoma. In this review, we analyze the literature data reporting the incidence of lung cancer after lung transplantation with its inherent risk factors, and we summarize the available data on possible treatment of lung cancer by lung transplantation. Finally, bronchial epithelial chimerism as possible cause for lung cancer is discussed.
\end{abstract}

Copyright $\odot 2011$ S. Karger AG, Basel

\section{Introduction}

Lung transplantation is nowadays considered a good therapeutic option for selected patients with end-stage pulmonary disease, not amenable to other treatment op- tions. The main indications are chronic obstructive pulmonary disease (COPD)/emphysema ( $\alpha_{1}$-antitrypsin deficiency included), cystic fibrosis, pulmonary fibrosis (usual interstitial pneumonia, as well as more rare indications such as sarcoidosis, histiocytosis and connective tissue-related disease) and pulmonary hypertension [1]. Although the results have improved significantly in recent years, 5-year survival is still inferior compared to other solid organ transplantations [2]. The main reasons can be found in the development of chronic lung allograft dysfunction and infections [3].

Also, solid organ tumors such as tumors originating from the bladder, lung, breast, prostate, liver and colon were reported in about $4 \%$ of 5 -year survivors [3]. In general, malignancies, other than lymphoma, were responsible for about $8-11 \%$ of mortality more than 3 years after lung transplantation [3].

Previous articles in this series: 1. Rooney $\mathrm{C}$, Sethi $\mathrm{T}$ : The epithelial cell and lung cancer: the link between chronic obstructive pulmonary disease and lung cancer. Respiration 2011;81:89104. 2. Adcock IM, Caramori G, Barnes PJ: COPD and lung cancer: new molecular insights. Respiration 2011;81:265-284. 3. Königshoff M: Lung cancer in pulmonary fibrosis: tales of epithelial cell plasticity. Respiration 2011;81:353-358.

\section{KARGER \\ Fax +4161306 1234 \\ E-Mail karger@karger.ch}

www.karger.com
(C) 2011 S. Karger AG, Basel

$0025-7931 / 11 / 0816-0441 \$ 38.00 / 0$

Accessible online at:

www.karger.com/res
Prof. Geert M. Verleden

Lung Transplantation Unit, University Hospital Gasthuisberg

49, Herestraat

BE-3000 Leuven (Belgium)

Tel. +32 1634 6805, E-Mail geert.verleden@uzleuven.be 
Lung cancer, more specifically, is reported to be 20-25 times higher in transplant patients compared to the general population, with an incidence of 0.28 and $4.1 \%$ in patients after heart and lung transplantation, respectively [4]. This has been attributed to a number of potential factors which are likely to be additive, including previous cigarette smoking, advanced age at transplantation and use of long-term immunosuppressive treatment [5].

In this paper, we will summarize what is currently known about the link between lung transplantation and lung cancer and will address 3 key questions: (1) what is the existing literature evidence for an increased prevalence of lung cancer in lung transplant patients? (2) Can lung transplantation be considered as a treatment option for lung cancer? (3) What is the role of epithelial chimerism in the development of lung cancer after lung transplantation?

\section{Is There Literature Evidence for an Increased Prevalence of Lung Cancer after Lung Transplantation?}

Malignancy has long been observed as a complication of chronic immunosuppressive therapy, and the cumulative risk of developing one or more malignancies (excluding non-melanoma skin cancer) in transplant recipients with a functioning graft is about $30 \%$ after 20 years. Indeed, skin and lymphoproliferative disorders are the most common cancers occuring, also after lung transplantation, with a prevalence in this scenario of 8 and $1.8 \%$, respectively, in 5-year survivors [3]. In the general population, bronchogenic carcinoma (BC) is the leading cause of cancer-related mortality, and although older reports could not demonstrate an increased prevalence in for instance kidney transplant patients [6], more recently, it was shown that the prevalence after thoracic transplantation was drastically increased.

Dickson et al. [7] published that 9/131 (6.9\%) single lung transplant recipients developed primary lung cancer after a mean of 52 months following the procedure; 8 were transplanted for COPD/emphysema, 1 for idiopathic pulmonary fibrosis (IPF). In contrast, none of their 131 double lung transplant patients developed such a malignancy. Most lung cancers were squamous cell cancers (6/9), 2 were adenocarconomas and 1 a carcinosarcoma. All cancers presented in the native lung. Survival after diagnosis was only $25 \%$ at 5 years, despite the fact that 5 patients underwent initial surgical resection. The risk factors for development of a primary lung cancer after transplantation were increasing age, smoking history of $>60$ pack-years and having received a single lung transplant [7].

In another series from the Cleveland clinic, 12 out of 520 lung transplant recipients $(2.3 \%, 7$ men) developed primary lung cancer at a mean of 119 weeks ( 27.7 months) after the transplant procedure. All except for 1 patient (IPF) had underlying COPD/emphysema. They were all ex-smokers, with at least a 30 pack-year history of smoking. Again, 11/12 cancers developed in the native lung. Cancer cell types included small cell lung carcinoma $(\mathrm{n}=$ $2)$, adenocarcinoma $(n=4)$, large cell $(n=3)$ and squamous cell $(\mathrm{n}=3)$ carcinoma. At diagnosis, 5 patients already had metastatic disease, 4 were not operable because of pleural involvement or poor pulmonary function, and 3 were surgically treated, of whom 1 died of sepsis after 2 weeks. In this series, the 2-year mortality was $83 \%$ [8].

In this paper, the authors also incorporated all published cases until 2006 and found another 47 patients who had developed primary lung cancer [8]. At transplantation, they had a mean age of 58 years, $76 \%$ had underlying COPD/emphysema, 19\% IPF and 91\% underwent a single lung transplantation. Also, $83 \%$ had an active smoking history. Forty percent of the patients underwent surgical resection, whereas $30 \%$ had either palliative or no treatment in view of the extensive nature of the disease. The overall 1-year survival was $57 \%$.

Roithmaier et al. [9] compared the incidence and type of malignancies in heart and or lung transplant recipients at their institution (Vic., Australia) and found 102 cancers in a series of 907 transplants, which corresponds to a 7.1-fold increase in incidence compared with the nontransplant population. They found an incidence of 251 lung cancers per 100,000 person-years, corresponding with a 9.3-fold increased risk after cardiopulmonary transplantation. They found no difference in incidence of any cancer between heart or heart-lung and lung transplanted patients, but they give no specific data on lung cancer. In their whole series, 12 patients developed lung cancer, but we have no information regarding the underlying transplantation type. All these patients died; however, we do not know after how much time.

In a series of 572 heart transplant patients, Potaris et al. [10] found 10 primary lung cancers (1.7\%) at a mean of 62.4 months following transplantation. Nine were heavy smokers ( $>60$ pack-years) and 1 was a pipe smoker. Seven patients were operated, 3 were inoperable at diagnosis and were treated with chemotherapy \pm radiotherapy. The mean survival of the 10 patients was 16.5 months [10]. 


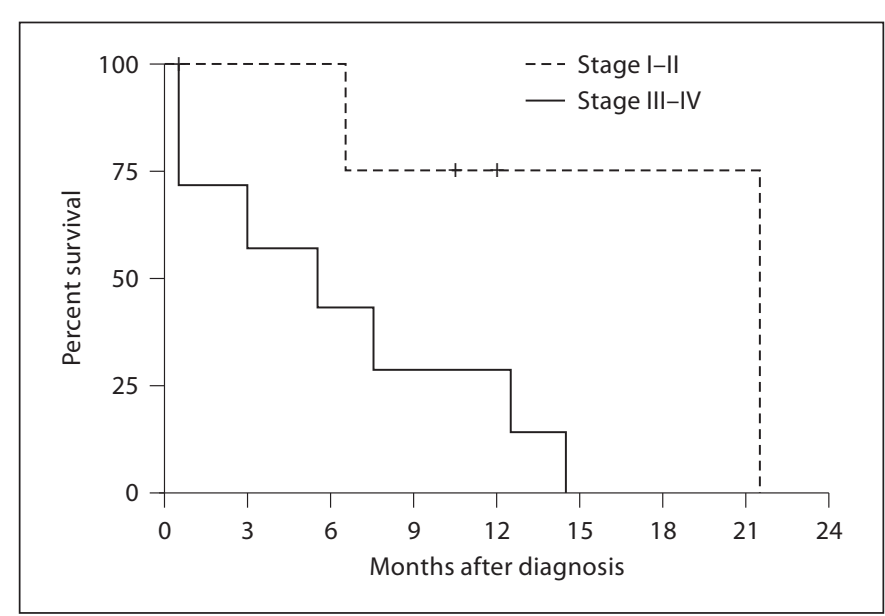

Fig. 1. Actuarial survival in 8 patients with stage III-IV and 4 patients with stage I-II disease. There is a clear trend for a better survival in early stages $(\mathrm{p}=0.052)$.

Recently, the incidence of bronchial carcinoma in our lung transplant population in Leuven was analyzed. From January 2000 until December 2010, 470 lung and heart-lung transplantations were performed, of whom 12 patients (2.6\%, 8 males) developed a primary BC at a mean of $37.8( \pm 24.3)$ months after transplantation. They were all ex-smokers and were transplanted at a mean age of 57.5 ( \pm 5.1 ) years; 8 patients were transplanted for COPD/emphysema and 4 for IPF. Since it is known from the literature that most lung transplant patients who develop $\mathrm{BC}$ had underlying COPD/emphysema or IPF, we only included such patients in the further analysis. In fact, 8/86 (9.3\%) of the single lung transplant patients developed a primary $\mathrm{BC}$, all in their native lung, in contrast to only $4 / 179$ double lung transplant patients $(2.2 \%$; $\mathrm{p}=$ 0.021 , Fisher's exact test). At diagnosis, 4 patients had a stage I-II disease, whereas all others had stage III-IV. Histologically, there were 11 non-small cell lung cancers (6 adenocarcinomas, 2 squamous carcinomas, 3 undefined) and 1 small cell lung cancer. Five patients were surgically treated; however, 1 had unforeseen N2 disease with additional pleural metastasis at surgery. All other patients (except 2 who died very soon after diagnosis) were treated with chemotherapy \pm radiotherapy. The median survival after diagnosis was only 7.5 months, with an almost significant survival difference between patients with stage I-II versus stage III-IV disease $(\mathrm{p}=$ 0.052 ). The latter patients had a median survival of only 5.5 versus 21.5 months for the stage I-II BC patients (fig. 1).

Lung Transplantation and Lung Cancer
From all these data, it can be concluded that primary BC occurs in about $2.2-2.3 \%$ of all (heart-)lung transplant patients, especially in the native lung after single lung transplantation with an incidence between 6.9 and $9.3 \%$. Tumors are diagnosed between 27.7 and 52 months after transplantation. More than $50 \%$ of patients already have stage III or higher disease at diagnosis, which means that treatment options are rather poor, although patients with lower-stage (operable) disease tend to do better. Increasing age at transplantation, a history of heavy smoking and a single lung transplant constitute the major risk factors. Since the incidence of primary BC is statistically lower after double lung transplantation, one may surely question the role of single lung transplantation in patients with COPD/emphysema and IPF and that is one of the reasons why Leuven and many centers worldwide have shifted to double lung transplantation in more than $95 \%$ of these patients.

\section{Can Lung Transplantation Be Considered as a Treatment Option for Lung Cancer?}

This remains a difficult question, although there is no doubt that for a classical BC (small cell or non-small cell) the answer is likely to be universally 'no' in view of the bad outcome even after curative surgery. Nevertheless, the very first lung transplantation in man was performed for an underlying stage IIIB bronchial carcinoma [11].

In a report from the Toronto group, 6 out of a total of 852 lung transplant patients were identified with a $\mathrm{BC}$ in the resected native lung. One of these patients underwent single lung transplantation for a recurrent bronchioloalveolar cell carcinoma (BAC). The remaining 5 patients received a double lung transplant for end-stage pulmonary disease. The tumor was detected during preoperative assessment in 2 patients, and in the other 3 patients, it was found during pathological examination of the explanted lungs. In 1 patient in whom BC was diagnosed before the transplantation procedure, further examination of lymph nodes during the transplantation procedure revealed an $\mathrm{N} 2$ disease. Three patients died of malignant dissemination between 5 and 35 months after transplantation. Two patients with BAC were alive without recurrence at 12 and 13 months, respectively. It was concluded from this report that lung transplantation cannot be supported in patients with a preoperative known diagnosis of $\mathrm{BC}$, except perhaps for BAC [12].

In another multicenter survey study investigating the outcome of patients who were transplanted with a BC in

Respiration 2011;81:441-445 
the native lung, a group of 69 patients was collected from 33 centers. Advanced multifocal BAC was the primary indication for transplantation in 26 patients of whom 13 developed a recurrence. The overall 5-year survival in this patient group was $39 \%$, which is significantly worse than the median survival in a non-malignant lung transplant population. An incidental BC (stage I, $\mathrm{n}=22$; stage II, $\mathrm{n}=12$; stage III, $\mathrm{n}=2$ ) or an incidental multifocal BAC was found in the explanted lung of the remaining 43 patients. The 5 -year survival was $51 \%$ in patients with stage I disease, only $14 \%$ in those with stage II and III disease and $23 \%$ in those with incidental BAC. Time from transplantation to recurrence and from recurrence to death was significantly longer in patients with multifocal BAC compared to all other types ( 17 vs. 5 months, $\mathrm{p}=0.001$, and 14 vs. 3 months, $p=0.0005$, respectively). It was concluded from this international survey that transplantation remains a valuable option for patients with impending respiratory failure due to multifocal BAC [13]. However, due to ethical considerations, this indication is not accepted in a lot of transplant centers over the world. This relates to the question as to whether these patients can have a normal waiting time or need urgent transplantation, potentially compromising other patients on the waiting list.

Of 214 patients transplanted at the Cleveland Clinic, 4 incidental neoplasms were found in the explanted lungs (2\%). There were 3 adenocarcinomas and 1 squamous cell carcinoma, 3 stage III and 1 stage IV disease. The overall 5 -year survival was $25 \%$, whereas it was $40.6 \%$ in all other lung transplant patients from that center [14].

Donor-transmitted $\mathrm{BC}$ is a very rare finding, and so far, only some case reports have been published. De Soyza et al. [15] described the first patient who was diagnosed with a metastatic small cell lung cancer 13 months after the transplantation procedure. Genetic testing of the tumor and recipient tissue demonstrated that the tumor originated from the donor. The tumor did not respond to chemotherapy and the patient died 1 month later. Since more and more transplantations are performed with marginal donors, being for instance smokers or heavy exsmokers, it remains of crucial importance to closely investigate the donor lungs at retrieval. This may be the only way to prevent transplanting a tumor, although in the particular case of De Soyza et al. [15] it is remarkable that the tumor was diagnosed only after 13 months, suggesting that it was not macroscopically present at transplantation but developed later.

Lung transplantation for metastatic malignant disease is even more anecdotal and, in Leuven, we only have ex- perience with 2 patients who were transplanted for a hemangioendothelioma. The first patient underwent a liver transplantation and had to undergo a bilateral lung transplantation a couple of years later because of recurrent disease in the lung with respiratory insufficiency. During the transplantation procedure, diffuse pleural and pericardial metastatic disease was found; nevertheless, this patient is still alive 7.5 years later, and only recently has recurrence of the disease in the liver transplant been diagnosed. The second patient underwent a combined liver and double lung transplantation, whilst she already had metastatic disease in the vertebrae. She is doing well with stable disease 2 years after the transplant procedure.

\section{What Is the Role of Epithelial Chimerism in the Development of Lung Cancer after Lung Transplantation?}

The occurrence of $\mathrm{BC}$ in the remaining native lung after contralateral single lung transplantation suggests that the immunosuppressive treatment on top of a (heavy) smoking history is the driving force for the carcinoma to develop. It is indeed widely accepted that immunosuppressive drugs (specifically, but not only, calcineurin blockers such as cyclosporine and tacrolimus) which depress the immune system act together with other known risk factors (such as cigarette smoke for lung cancer and ultraviolet exposure for skin cancer) to induce carcinogenesis [16]. This may occur for instance via inhibition of phosphatase and tensin homolog deleted on chromosome 10 , which is a known tumor suppressor [16]. Impaired Tcell functioning, as in HIV-infected patients, may indeed increase the incidence of, for instance, lung cancer [17].

It seems evident that most lung cancers (certainly in the remaining native lung) arise from the recipient. However, in their case report, De Soyza et al. [15] describe the donor origin of a small cell lung cancer, and in another report, it was shown that even after double lung transplantation, a newly detected BC may still arise from the recipient. In the latter report, a small cell lung carcinoma was diagnosed in a 25-year-old female cystic fibrosis patient who underwent double lung transplantation from a male donor. One year after transplantation, the tumor was diagnosed and proved to be of recipient origin, since the tumor cells were of female gender [18]. This case report illustrates the existence of bronchial chimerism after lung transplantation. This chimerism has clearly been illustrated in several reports. In an elegant study from the Munich group, it was demonstrated that the endothelial 
cells and bronchial and alveolar epithelium retained the donor sex type, whereas the lymphocytes of the donor are almost completely replaced by recipient cells [19]. In another study, clear integration of recipient-derived cells was found in the bronchial epithelium, in type II pneumocytes and in seromucous glands. Moreover, quantitative analysis showed that the epithelial structures displaying signs of chronic injury (such as squamous metaplasia) showed a markedly increased degree of chimerism (24 vs. 9.5\%) [20]. In children, following sex mismatched lung transplantation, transbronchial biopsies demonstrated evidence of chimerism as early as 3 weeks after the transplantation and this remained relatively constant up to 37 months [21]. It is assumed that host stem cells or progenitor cells replace lung cells in the transplanted lung, which are lost as a consequence of the various injury processes (reperfusion injury, acute rejection, infection) associated with lung transplantation [21].

\section{Conclusion}

$\mathrm{BC}$ is most frequently diagnosed in the remaining native lung after contralateral single lung transplantation. Single lung transplantation for IPF and COPD/emphysema, together with a heavy smoking history, increasing age at transplantation and the immunosuppressive treatment remain the most important risk factors.

After double lung transplantation, the tumor may originate from the donor as well as from the receptor, illustrating the chimerism that occurs after transplantation. The prognosis remains poor, although patients with a stage I and II disease tend to have a better survival.

There is some evidence that patients with a BAC and impending respiratory insufficiency may benefit from a double lung transplantation, although this issue with its ethical considerations is still open for debate, and many centers do not accept these patients as valuable lung transplant candidates.

\section{References}

1 Verleden GM, Fisher AJ: Indication, patient selection and timing of referral for lung transplantation. Eur Respir Monogr 2009; 45:1-5.

2 Sayegh MH, Carpenter CB: Transplantation 50 years later - progress, challenges, and promises. N Engl J Med 2004;351:2761-2766.

-3 Christie JD, Edwards LB, Kucheryavaya AY, Aurora P, Dobbels F, Kirk R, Rahmel AO, Stehlik J, Hertz MI: The Registry of the International Society for Heart and Lung Transplantation: twenty-seventh official adult lung and heart-lung transplant report - 2010. J Heart Lung Transplant 2010; 29:1104-1118.

4 Bellil Y, Edelman MJ: Bronchogenic carcinoma in solid organ transplant recipients. Curr Treat Options Oncol 2006;7:77-81.

5 Buell JF, Gross TG, Woodle ES: Malignancy after transplantation. Transplantation 2005; 80:S254-S264.

6 Arcasoy SM: Controversies in bronchogenic carcinoma following lung transplantation. J Thor Oncol 2008;3:1377-1378.

7 Dickson RP, Davis RD, Rea JB, Palmer SM: High frequency of bronchogenic carcinoma after single-lung transplantation. J Heart Lung Transplant 2006;25:1297-1301.

$\checkmark 8$ Minai OA, Shah S, Mazzone P, Budev MM, Sahoo D, Murthy S, Mason D, Pettersson G, Mehta AC: Bronchogenic carcinoma after lung transplantation: characteristics and outcome. J Thor Oncol 2008;3:1404-1409.
9 Roithmaier S, Haydon AM, Loi S, Esmore D, Griffiths A, Bergin P, Williams T, Schwarz MA: Incidence of malignancies in heart and/ or lung transplant recipients: a single-institution experience. J Heart Lung Transplant 2007;26:845-849.

10 Potaris K, Radovancevic B, Thomas CD, Gregoric I, Vaporciyan AA, Riggs SA, Radovancevic R, Vaughn WK, Frazier OH: Lung cancer after heart transplantation: a 17-year experience. Ann Thorac Surg 2005;79:980983.

11 Hardy JD, Webb WR, Dalton ML Jr: Lung homotransplantation in man. JAMA 1963; 186:1065-1074.

12 De Perrot M, Fischer S, Waddell TK, Struevber M, Harruibnger W, Pierre AF, Spiliopoulos A, Haverich A, Keshavjee S: Management of lung transplant recipients with bronchogenic carcinoma in the native lung. J Heart Lung Transplant 2003;22:8789.

13 De Perrot M, Chernenko S, Waddell TK, Shargall Y, Pierre AF, Hutcheon M, Keshavjee S: Role of lung transplantation in the treatment of bronchogenic carcinomas for patients with end-stage pulmonary disease. J Clin Oncol 2004;22:4351-4356.

14 Abrahams NA, Meziane M, Ramalingam P, Mehta A, DeCamp M, Farver CF: Incidence of primary neoplasms in explanted lungs: long-term follow-up from 214 lung transplant recipients. Transplant Proc 2004;36: 2808-2811.
15 De Soyza AG, Dark JH, Parums DV, Cutis A, Corris PA: Donor-acquired small cell lung cancer following pulmonary transplantation. Chest 2001;120:1030-1031.

16 Han W, Ming M, He T-C, He Y-Y: Immunosuppressive cyclosporine A activates AKT in keratinocytes through PTEN suppression. J Biol Chem 2010;285:11369-11377.

17 Kirk GD, Merlo C, O’Driscoll P, Mehta SH, Galai N, Vlahov D, Samet J, Engels EA: HIV infection is associated with an increased risk for lung cancer, independent of smoking. Clin Infect Dis 2007;45:103-110.

18 Picard C, Grenet D, Copie-Bergman C, Martin N, Longchampt E, Zemoura L, Stern M: Small-cell lung carcinoma of recipient origin after bilateral lung transplantation for cystic fibrosis. J Heart Lung Transplant 2006;25: 981-984.

19 Bittmann I, Dose T, Baretton GB, Müller C, Schwaiblmair M, Kur F, Löhrs U: Cellular chimerism of the lung after transplantation. Am J Pathol 2001;115:525-533.

20 Kleeberger W, Versmold A, Rothämel T, Glöckner S, Bredt M, Haverich A, Lehmann $\mathrm{U}$, Kreipe H: Increased chimerism of bronchial and alveolar epithelium in human lung allografts undergoing chronic injury. Am J Pathol 2003;162:1487-1494.

21 Spencer H, Rampling D, Aurora P, Bonnet D, Hart SL, Jaffé A: Transbronchial biopsies provide longitudinal evidence for epithelial chimerism in children following sex mismatched lung transplantation. Thorax 2005;60:60-62. 